\title{
A SHORT REAPPRAISAL OF THE PRINCIPLES OF TREATMENT IN CEREBRAL PALSY
}

S. Irwin-Carruthers, Nat. Dip. Physio. (Pta.), Teaching Dip. Physio. (Pta.)*

\section{INTRODUCTION}

In recent years much emphasis rightly has been placed on an approach to the treatment of cerebral palsy based upon sound neurophysiological principles. Dr. and Mrs. Bobath have contributed the most fully developed and well documented approach to the treatment of the disturbances of motor function found in cerebral palsy and their work provides a sound and realistic overall concept of treatment. Other workers in this field have not always followed the same principles, although some, such as Professor Rood, have provided techniques which in selected instances may be of value in obtaining specific responses. Whilst it is necessary to have a knowledge of the various approaches to treatment, the dangers of an electric approach which utilizes opposing philosophies of treatment cannot be over-stressed. We are dealing with a child whose motor development, for a variety of reasons, is going to be abnormal - and this abnormal *Currently Lecturer in Physiotherapy, University of
Stellenbosch. motor development is going to take place along certain predictable pathways. We know in advance, to a great extent, what abnormal primary and compensatory synergies are going to appear and our treatment is directed towards preventing these from the moment of the child's first assessment. To change from, say, Bobath to Rood to proprioceptive neuromuscular facilitation to splintage and eventually surgery during different stages of a child's development displays not only a break-down in understanding of the disurbances of motor function involved but also a break-down in the execution of the original approach to treatment.

Bearing in mind that in South Africa we usually see these children within the first year of life we are in a position to influence his motor development whilst still acknowledging his limits of attainment. The young child develops his body image in the first eighteen months and his basic postural patterns during the first three years of life, and by five years of age has so perfected his movement patterns that he is ready for the learning of skills. Further perceptual development follows on the establishment of basic sensori-motor patterns - requiring these patterns for development 
and, in turn, being a necessary pre-requisite for conceptual development.

Early treatment of the cerebral palsied child (witinin the first eighteen months of life, and preferably within the first nine months) affords the best potential for adjustment to cerebral damage through the experience of normal sensori-motor patterns and the consequent development of more normal motor skills. In older children, who have only experienced abnormal motor patterns and have thus reinforced these patterns in the attainment of function - often to the extent of producing fixed contractures and deformities - the potential for improvement is much less. Even in these cases, however, something can be done towards inhibition of spasticity and reorganisation of motor patterns, but it is important to recognize that the older child has structured his reactions, however abnormal, in order to enable him to cope with the demands made upon him. The psychological effect of injudicious handling which too hastily breaks down his carefully structured responses and displays their inadequacies can be very disturbing to the child.

Whatever the age of the child we can only help him in developing and exploiting his pre-existing potentialities, both physical and intellectual. There have, unfortunately, been workers overseas whose extravagant claims on the physical and intellectual responses to treatment have endangered the reputation of this approach to treatment. in order to avoid any such wild claims and to give neurodevelopmental treatment the recognition it deserves, it is necessary to analyse the underlying principles and to establish the aims of treatment.

\section{PHILOSOPHY OF TREATMENT}

As far back as 1926 Magnus attempted to direct attention to the underlying adaptive changes of posture which provide the constantly changing background for movement. It is these postural patterns which provide the key to the treatment of cerebral palsy, as well as of other disturbances of motor function.

The normal child develops his postural reflex mechanism through the interaction of two sets of automatic reactions:

1. The righting reactions:

The righting reactions were first analysed by Schaltenbrand. Their sequence of development starts at birth, and enables the child to control the position of his head in space as well as the alignment of the various body parts." Through interaction of the different righting reactions the child learns to roll over and sit up in a typical pattern of rotation around the body-axis, which persists until the development of equilibrium reactions serves to modify this sequence of events,

2. The equilibruim reactions:

As first described by Weisz, the equilibruim reactions are highly sensitive adjustments to postural variations which only start to make an appearance at around 6 months of age. They are the most highly developed of the automatic movement patterns and only become perfected in the fifth year of life, by which stage they have already suppressed certain of the earlier righting reactions.

Intact righting and equilibrium reactions are the essential prerequisite for motor function. They can only occur in the presence of "normal" muscle tone, i.e. the tone must be high enough to provide a stable postural background but low enough to allow movement to occur.

The cerebral-palsied child does not have the opportunity to develop normal righting and equilibrium reactions. The reason is twofold, firstly his level of motor development is arrested or retarded, and secondly he is subject to abnormal postural reflex activity which causes abnormalities of muscle tone and limits his reactions to "set" patterns of movement. In assessing the child it is important to distinguish between these primitive and pathological factors.

It is essential to realise that the normal baby develops his first postural patterns in response to the handling he received from his mother. These early sensori-motor patterns form the basis of all further postural adaptations and skilled movement. Through them the baby learns to control first his head, then his trunk, and later on to use his limbs for support whilst in answer to his progressive independence the mother automatically reduces the degree of support which she affords him. Where the muscle tone is too high (or too low) to allow these normal responses to handling, the baby experiences only abnormal postures and movements, and because these are his only experience he has to utilise these abnormal patterns to obtain voluntary movement later on. Through inhibition of abnormal postural reflex activity and facilitation of normal righting and equilibrium reactions th child can be given the experience of normal posturl) background patterns which is so necessary for the development of future skilled movement.

The fact that the normal infant's first reactions are automatic and not volitional leads us to another important treatment principle-that of automatic (Bobath) or subcortical (Rood) movements or postural patterns. Volitional activity will result in the reproduction of abnormal patterns of movements and will therefore strengthen these abnormal patterns. Automatic movements, which are no less active in nature, allow normal sensori-motor experience and have the additional advantage of not requiring the child's active co-operation. As the child gains increasing control over his movement patterns, all degrees of volitional activity may be obtained, from "most automatic" to "least automatic", the therapist's control being gradually withdrawn.

\section{AIMS OF TREATMENT}

The aims of treatment are:

1. To provide normal sensori-motor experience, and therefore:

2. To counteract the development of, or to inhibit, abnormal postural reflex activity:

This will include inhibition of spasticity in the spastic child, whereas other children may need proprioceptive and exteroceptive techniques for selective increase of muscle tone in order to pro vide a stable postural background for movement and co-ordination of agonists and antagonists.

3. To facilitate

(a) basic postural movement patterns, and later: (b) skilled motor patterns, on the basis of a more normal muscle tone.

4. To prevent contractures and deformities in young children and correct them, where possible, in older children.

\section{PLANNING OF TREATMENT}

A detailed knowledge of normal development and skill in handling and assessing are needed when planning treatment.

The following aspects must be evaluated:

1. How much of the child's disability is due to each of the two basic disturbances of motor function? (a) abnormal postural patterns (pathological)? (b) retarded motor development (primitive)? Although there is a certain degree of overlap and differentiation may be difficult, it is important to attempt this differentiation. Young infants may, appear primarily primitive but may show "soft" signs which become more definitely pathological on 
stimulation or excitation. If these are truly pathological they will become definite after about four months of age, as extension develops. Primitive patterns are basically normal and should be recognized in order to retain and build upon them. It cannot be assumed that a primitive pattern will be retained automatically - as the child gets older, primitive patterns are often entirely replaced by spastic patterns. In order to retain them they must be utilized early in treatment.

2. What is the type and degree of muscle tone?

What is the child's "basic" tone when he is comfortably at rest?

How does stimulation alter his basjc state?

Does he show changes on fast movement, effort, loss of balance, talking, etc.?

3. How do his abnormal postural patterns influence functional activities in the developmental sequence? Is his posture basically symmetrical or asymmetrical?

Does his abnormal activity interfere with static postures (prone, supine, sitting, kneeling, standing)? Does his abnormal activity interfere with movement (lifting head, rolling, supporting on hands, sitting up, using hands in midline, crawling, standing up and walking)?

What is the effect on head control, balance and protective reactions?

What associated reactions are present?

4. What is the child's level of motor development? Is his level of ability consistent at one level of development? or

Does he show a "scatter" of abilities at various levels? If so, what are the most important gaps which need filling in?

At what level should treatment commence?

5. What is the child's chronological age?

Is there time (i.e. is the child young enough) to pass through all the developmental stages?

Or, in an older child, must we limit our object to filling-in important gaps?

What is the limit of potential?

6. What is the distribution of extent of involvement? Can he compensate via less affected parts of the body? Or, is over-compensation preventing him from reaching his full potential?

7. Are contractures or deformities already present?

What abnormal postural patterns have caused or will tend to cause them?

Can they be prevented?

How much is structural and how much can be corrected by inhibiting spasticity?

From this assessment the program and technique of treatment can be determined. In the young child, where strong tonic patterns have not yet developed, facilitation of movement progresses simultaneously with inhibition of abnormal postural patterns. In the older child with fixed postural patterns or even contractures, more emphasis may have to be laid on inhibition although righting and equilibrium reactions are facilitated as soon as possible. Static reflex-inhibiting postures should be avoided. Stimulation must be adequate to obtain a response, but carefully graded to prevent unwanted activity. Grading of stimulation is especially important where tone is low or fluctuating. Movement should never be demanded against the resistance of hypertonus - the therapist must ascertain that the muscle tone is normal before attempting movement, and must cease movement as soon as the child ceases to follow. As well as preparing the child for movement, the physiotherapist must allow him sufficient time in which to react, in order to elicit an active automatic reaction and avoid mere passive movement. Although one stage in development leads to another, it is a mistake to think that one stage must be perfected before progressing to the next. There is much overlap in the normal developmental sequence, this being especially true with regard to balance and equilibruim reactions which always lag one stage behind - for instance the child begins to walk before he has perfected his equilibruim reactions in sitting and kneeling. Moreover, facilitation of equilibrium reactions can begin whilst a certain degree of support is still necessary for the position in which they are being elicited. It is, however, essential that the child should not be pushed beyond the developmental level for his chronological age.

As a general rule no stage in the developmental sequence should be completely omitted, but it is quite often necessary to avoid certain (otherwise normal) postural patterns in children where repetition of these patterns would lead to reinforcement of abnormal motor patterns, e.g. bridging in athetoid quadriplegia may reinforce extensor spasms, kicking may cause scissoring and the consequent development of a grossly abnormal gait, crawling on all fours may increase flexor spasticity, and forward support on extended arms may increase flexor spasticity in the shoulders and trunk unless abduction and lateral rotation is established first.

\section{THE ARGUMENT AGAINST SPLINTAGE AND} SURGERY

Bracing, splinting and even special boots are preferably avoided in the treatment of cerebral palsy. The disadvantages include increasing or shunting of spasticity, altered proprioceptive input, increase of asymmetry and the learning of additional "abnormal" postures and patterns of movement. Circulatory changes are also a problem.

Increase of spasticity can occur even when the splint is maintaining the limb in a more "favourable" position. This is because, in cerebral palsy, it is almost always the action of flexors, adductors and internal rotators which we wish to inhibit - and these muscles unfortunately fall into the group where sustained stretch results in auto-facilitation, and furthermore in inhibition of the antagonists of the spastic muscle groups.

Shunting of spasticity is an ever-present danger whenever a limb is held fixed in one position. Even simple splintage of the hemiplegic hand can result in increased flexor spasticity at elbow and shoulder with depression of the shoulder-girdle, increased flexor spasticity in the trunk, retraction of the pelvis, increased extensor spasticity in the leg and consequent deterioration of the walking pattern.

Since our primary aim in treatment is to provide the child with more normal sensori-motor experience, the disadvantages of the altered proprioceptive and exteroceptive input (unavoidable with any splint) are obvious.

The argument against surgery is threefold. Firstly that of shunting of spasticity, secondly that of instability and thirdly that of attempting a mechanical solution to a neurophysiological problem. In addition, the post-operative splintage poses all the problems discussed above and the period of immobilization results in further sensori-motor deprivation.

Shunting of spasticity is due to the predetermined synergies of patterns of spasticity. Movement can only occur within these patterns, and when one component of a pattern is removed mechanically as a result of surgery, spasticity is likely to be shunted to the opposite mass pattern. This is very often even seen following simple tendo-Achilles lengthening, when the resulting increased dorsiflexion produces flexion at knee and hip, retraction of the pelvis, flexor spasticity in the trunk and increased flexion in the arm. For this reason, whenever a gastrocnemius recession and/or tendoAchilles lengthening does appear to be indicated, it is 


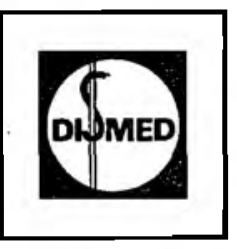

\section{THE}

\section{PRESENTS - Minidyme mk II \\ TRANSISTORISED FARADIC UNIT}

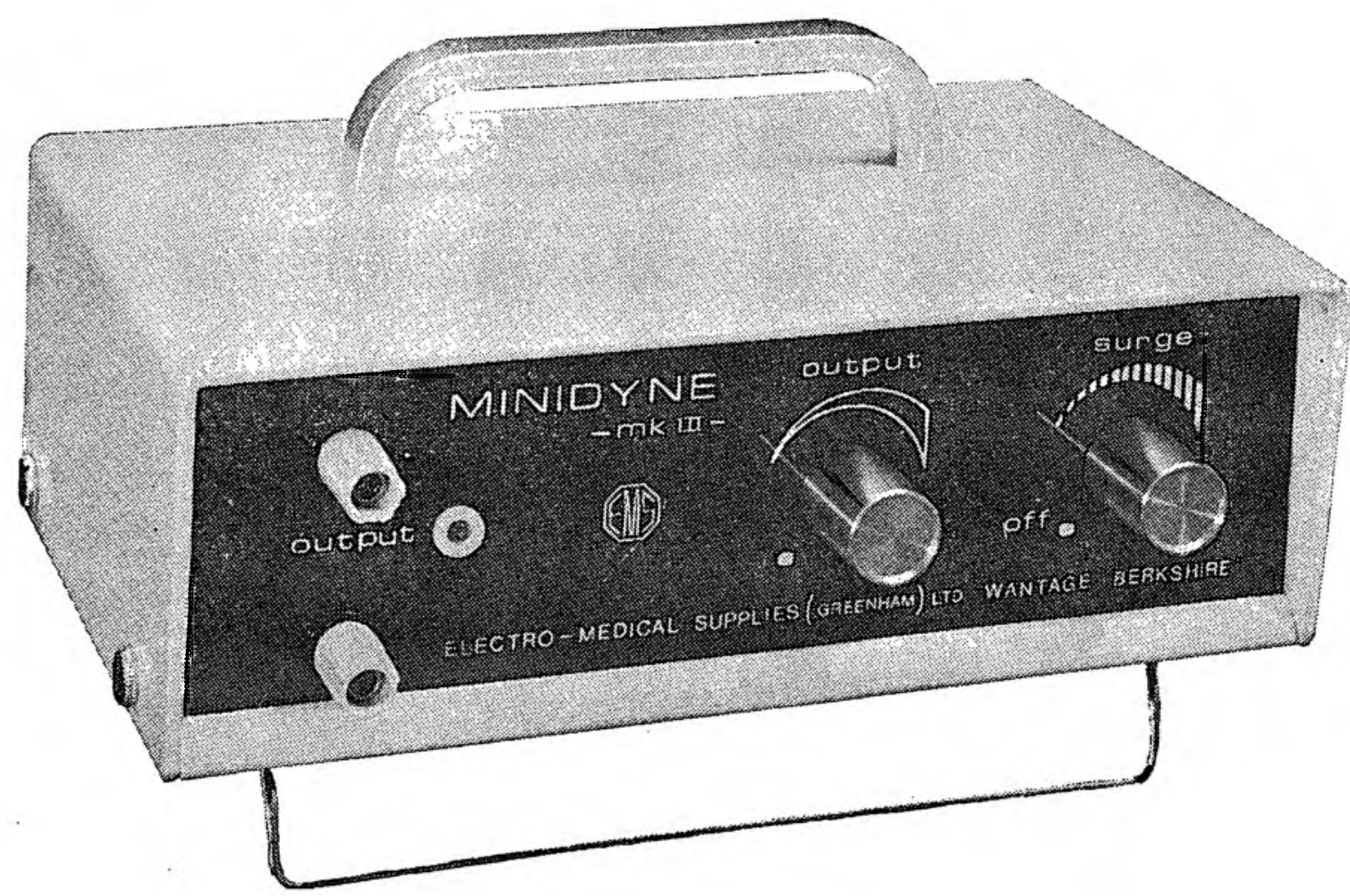

Representing another advance in the evolution of the Minidyne, the Mark III version incorporates printed circuits which reduce the size but also enhance the reliability: continuing features are

wide range of surge speed control with output sufficient for all forms of faradic techniques

audible as well as visual indication of surge speed enabling the operator to anticipate a muscle reaction without having to watch the control panel

fitted with Ever Ready PP9 batteries which will give up to six months' use without replacement and are obtainable worldwide

WEIGHT reduced to: $4 \mathrm{lbs}$. $(1,8 \mathrm{~kg})$

SIZE reduced to $8^{\prime \prime} \times 5 \frac{1}{2} " \times 2 \frac{1}{2} "(20 \mathrm{~cm} \times 13,5 \mathrm{~cm} \times 6 \mathrm{~cm})$.

PRICE:

R96,50

complete with accessories.

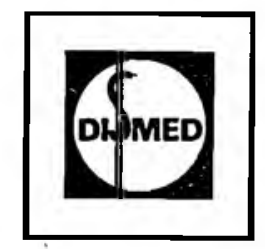

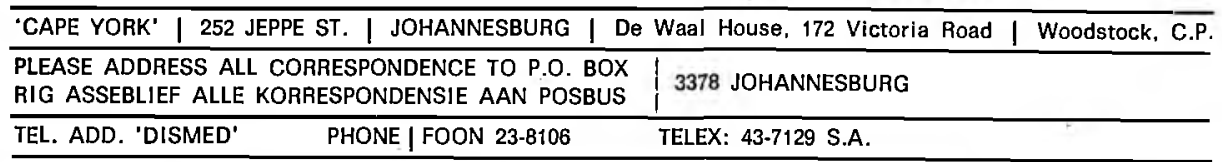


as well to try preliminary plasters to see whether the child will be able to cope with the increased flexion.

Instability is a particular problem following operaions around the hip joint. Pelvic instability is a probalmost all cerebral-palsied children, lem comm of them can tilt or rotate their pelvis or very few of their hips. How much greater the probactiveiy extend following transfer or release of muscles acting upon the hip joint and pelvis.

The solution would seem to be to prevent the need for extensive surgery, and the only indication for surgery would seem to be established deformities in the (antreated child. Certainly surgery should be avoided in a young child where there is so much potenvor influencing the postural tone and movement patterns by means of neurodevelopmental therapy pare are certainly far better ways of inhibiting a Moro reaction than by lengthening the hamstrings!

SUMMARY:

This article attempts a reappraisal of the concept of rodevelopmental therapy in cerebral palsy in the nope that this approach to treatment will be more consistently applied.

\section{REFERENCES:}

1. Bobath, K. and B.: The Treatment of Motor Disorders of Pyramidal and Extrapyramidal Origin by Reflex Inhibition and Facilitation of Movement, Physiother. (C.S.P.) 41, 5, May 1955.

2. Bobath, K. and B.: The Neuropathology of Cerebral Palsy and its Importance for Treatment and Diagnosis, Cereb. Palsy Bull., 1, 8 August 1959.

3. Bobath, K. and B.: An Analysis of the development of standing and walking patterns in patients with cerebral palsy, Physiother. (C.S.P.) 48, 6, June 1962.

4. Bobath, B.: Motor development, its effect on general development, and application to the treatment of cerebral palsy, Ibid.

5. Bobath, $K$. and B.: The facilitation of normal postural reactions and movements in the treatment of cerebral palsy, Physiother. (C.S.P.), 50, 8, August 1964.
6. Bobath, B.: Abnormal Postural Reflex Activity caused by Brain Lesions; London, Heinemann, 1965.

7. Bobath, B.: The very early treatment of cerebral palsy, Devel. med. child neurol., 9, 4, August 1967.

8. Bobath, B.: The Treatment of Neuromuscular Disorders by Improving Patterns of Co-ordination, Physiother. (C.S.P.), 55, 1, January 1969.

9. Bobath, K.: The normal postural reflex mechanism and its deviation in children with cerebral palsy, Physiother. (C.S.P.), 57, 11, November 1971.

10. Bobath, K.: The Motor Deficit in Patients with Cerebral Palsy, Clinics in Devel. Med. No. 23, London, Heinemann, 1972.

11. Finnie, N., Handling the Young Cerebral Palsied Child at Home, London, Heinemann, 1968.

12. Magnus, R.: Cameron Prize lectures on some results of studies in the physiology of posture, Lancet, ii, 531 (p. 585) 1926.

13. Rood, M. S.: The use of Sensory Receptor to Activate, Facilitate and Inhibit Motor Response, Autonomic and Somatic, in Developmental sequence; in: Approaches to the Treatment of Patients with Neuromuscular Dysfunction, Study Course VI, 3rd Occup. Ther. Conference, Dubuque, Iowa, Wm. C. Brown \& Co. 1964.

14. Schaltenbrand, G.: Some Observations on Development of Human Motility and on Motor Disturbances, Bull. New York Acad. Med., 3, 534, 1927.

15. Stockmeyer, S. A.: An Interpretation of the approach of Rood to the Treatment of Neuromuscular Dysfunction, Am. J. Phys. Med., 46, 1, February 1967.

16. Weisz, S.: Studies in Equilibruim Reaction, J. Nerv. Ment. Dis., 88, 150, 1938.

\section{ACKNOWLEDGEMENTS:}

Dr. and Mrs. K. Bobath, Mrs. J. Bryce, Prof. M. Rood and Mrs. E, Richardson - for post-graduate course notes and personal discussion. 